\title{
Study of MicroRNAs Related to the Liver Regeneration of the Whitespotted Bamboo Shark, Chiloscyllium plagiosum
}

\author{
Conger Lu, Jie Zhang, Zuoming Nie, Jian Chen, Wenping Zhang, \\ Xiaoyuan Ren, Wei Yu, Lili Liu, Caiying Jiang, Yaozhou Zhang, Jiangfeng Guo, \\ Wutong Wu, Jianhong Shu, and Zhengbing $\mathrm{Lv}$
}

Institute of Biochemistry, College of Life Sciences, Zhejiang Sci-Tech University, Hangzhou 310018, China

Correspondence should be addressed to Zhengbing Lv; zhengbingl@zstu.edu.cn

Received 13 June 2013; Accepted 28 July 2013

Academic Editor: Lei Chen

Copyright (C) 2013 Conger Lu et al. This is an open access article distributed under the Creative Commons Attribution License, which permits unrestricted use, distribution, and reproduction in any medium, provided the original work is properly cited.

To understand the mechanisms of liver regeneration better to promote research examining liver diseases and marine biology, normal and regenerative liver tissues of Chiloscyllium plagiosum were harvested $0 \mathrm{~h}$ and $24 \mathrm{~h}$ after partial hepatectomy $(\mathrm{PH})$ and used to isolate small RNAs for miRNA sequencing. In total, 91 known miRNAs and 166 putative candidate (PC) miRNAs were identified for the first time in Chiloscyllium plagiosum. Through target prediction and GO analysis, 46 of 91 known miRNAs were screened specially for cellular proliferation and growth. Differential expression levels of three miRNAs (xtr-miR-125b, fru-miR-204, and hsamiR-142-3p_R-1) related to cellular proliferation and apoptosis were measured in normal and regenerating liver tissues at $0 \mathrm{~h}, 6 \mathrm{~h}$, $12 \mathrm{~h}$, and $24 \mathrm{~h}$ using real-time PCR. The expression of these miRNAs showed a rising trend in regenerative liver tissues at $6 \mathrm{~h}$ and $12 \mathrm{~h}$ but exhibited a downward trend compared to normal levels at $24 \mathrm{~h}$. Differentially expressed genes were screened in normal and regenerating liver tissues at $24 \mathrm{~h}$ by DDRT-PCR, and ten sequences were identified. This study provided information regarding the function of genes related to liver regeneration, deepened the understanding of mechanisms of liver regeneration, and resulted in the addition of a significant number of novel miRNAs sequences to GenBank.

\section{Introduction}

Cartilaginous fish are jawed vertebrates that diverged from the common ancestor of humans and teleost fish approximately 530 million years ago [1]. Similar to teleost fish, cartilaginous fishes possess complex physiological systems, such as an adaptive immune system and a pressurized circulatory system [2]. The white spotted bamboo shark (Chiloscyllium plagiosum) is a cartilaginous fish that is widely distributed in cold seas along the coasts of the eastern Pacific. Economically, this shark is one of the most important marine animals, possessing both scientific and commercial food values. The liver of $C$. plagiosum, accounting for $75 \%$ of the weight of the viscera, possesses immune regulatory functions and contains bioactive substances. Several investigators have isolated and cloned stimulatory factors related to liver regeneration and immune regulation from Chiloscyllium plagiosum [3-6], but there have not yet been miRNAs reported for this species.
MicroRNAs (miRNAs) are a family of small, noncoding, and single-stranded RNAs that consist of approximately 19-25 nucleotides derived from the stem regions of hairpin transcripts (referred to as "pre-miRNAs"). These small RNAs act as regulators, leading to either mRNA cleavage or translational repression by complementarily hybridization to the $3^{\prime}$ untranslated regions ( $3^{\prime}$ UTRs) of their target mRNAs. The formation of mature miRNAs involves several steps. First, most miRNAs are transcribed as long primary transcripts (pri-miRNAs) by RNA Pol II, although a minor group of miRNAs associated with Alu repeats can be transcribed by RNA Pol III. The primary transcript is processed by the RNase III enzyme Drosha in the nucleus to give one or more 60-100 nt long hairpin precursor sequences (pre-miRNAs). Together with DiGeorge syndrome critical region gene 8 (DGCR8), Drosha forms a large complex known as the Microprocessor complex; DGCR8 interacts with pri-miRNAs and assists Drosha in cleaving the substrate. The hairpin 
precursor is then exported by Exportion-5 to the cytoplasm, where the mature miRNA is excised by another RNase III enzyme, Dicer. Following Dicer cleavage, the resulting $\approx 22$ nt RNA duplex is loaded into the Ago protein to create the effector complex, RISC. One strand of the $\approx 22$ nt RNA duplex remains with Ago as a mature miRNA and targets the $3^{\prime}$ UTR complementary pairing area of the target gene to approximately 2-8 bases of the $5^{\prime}$ end of the miRNA [79]. Negative posttranscriptional regulation by miRNAs has been observed in various biological processes, including viral disease [10], lipid metabolism [11], and cellular proliferation and differentiation [12].

Research into the mechanisms of liver cell growth and apoptosis has focused on individual signal molecules, important transcription factors, and related target genes and signaling pathways. Research has been less comprehensive, however, regarding the more analytical aspects of gene expression regulation. A substantial body of evidence has indicated that miRNAs are abundant in the liver and play an important role in liver development, disease, and regeneration [13-15]. In this study, we carried out deep sequencing in combination with bioinformatics and genomic sequencing to identify miRNAs in Chiloscyllium plagiosum liver. Although sequencing of Chiloscyllium plagiosum genome has not yet been completed, the Callorhinchus milii genome was recently proposed to be a model for cartilaginous fish genomes [16]. Therefore, we used the Callorhinchus milii genome to predict pre-miRNA hairpin structures. In this study, we characterized small RNAs and identified miRNAs in the $C$. plagiosum liver. We further analyzed miRNA clusters and the expression of Chiloscyllium plagiosum miRNAs. Our results may contribute to liver miRNA research not only for fish but also for other species. This is the first comprehensive report about the miRNA of cartilaginous fish and adds several novel miRNAs to the database, which will help to identify homologs in other species. In addition, screening differentially expressed genes in normal and regenerating liver tissues by DDRT-PCR will provide valuable information for further study of the newly discovered functional genes related to liver regeneration and the relationship between differentially expressed genes and miRNAs. We have laid the foundation for further understanding of the function of miRNAs in liver regulation in Chiloscyllium plagiosum.

\section{Materials and Methods}

2.1. Sample Preparation and Liver Excision. A live Chiloscyllium plagiosum was purchased from a Guangdong aquatic product market. Two-thirds of the liver was surgically removed, using a $2 \%$ chloral hydrate solution $(300 \mathrm{mg}$ per $\mathrm{Kg}$ weight of shark) as an anesthetic. The wound was then sutured, and the shark was placed into seawater to continue feeding. Regenerating liver tissues were obtained $0 \mathrm{~h}$ and $24 \mathrm{~h}$ after the partial hepatectomy $(\mathrm{PH})$ by opening the suture and removing the cut border of the left liver. These experiments complied with the relevant national animal welfare laws and were conducted under guidelines approved by the China Wildlife Conservation Association.
2.2. Small RNA Library Construction and Deep Sequencing. The total RNA of the liver was extracted using the mirVana miRNA Isolation Kit (Ambion, Austin, USA) according to the manufacturer's protocol. Small RNAs were size fractionated and ligated to the SRA $5^{\prime}$ adapter. This step was followed by SRA $3^{\prime}$ adapter ligation and size fractionation to isolate RNAs of 64-99 nt. The RNAs were then converted to singlestranded cDNA using Superscript II reverse transcriptase (Invitrogen, CA, USA) and Illumina's small RNA RT Primer. This pool was once again size fractionated to isolate cDNA in the $80-115$ bp range that contained miRNAs. Next, the cDNA was PCR-amplified for 20 cycles using Illumina's small RNA primer set and Phusion polymerase (New England Lab, USA). The PCR products were size fractionated and recovered for sequencing on a Genome Analyzer GA-II (Illumina, San Diego, USA) following the vendor's recommended protocol for small RNA sequencing. Following realtime sequencing, image analysis and base calling by Illumina's Real-Time Analysis version 1.8.70 (RTA v1.8.70), raw sequencing reads were obtained using Illumina's Sequencing Control Studio software version 2.8 (SCS v2.8). The extracted sequencing reads were then used for standard data analysis.

2.3. Standard Data Analysis. Following the removal of adapter sequences and low-quality reads, clean reads between 15 and 30 bases in length were processed for bioinformatic analysis. A proprietary pipeline script, ACGT101-miR v4.2 (LC Sciences) [17, 18], was used for the sequencing data analysis. Various "mappings" were performed with unique sequences against pre-miRNAs and mature miRNAs sequences from selected species (Danio rerio, Fugu rubripes, Oryzias latipes, Xenopus laevis, Xenopus tropicalis, Homo sapiens, and Mus musculus) listed in the miRBase v19.0 (http:// www.mirbase.org/) as well as the genome of Callorhinchus milii (http://esharkgenome.imcb.a-star.edu.sg/resources .html). The mapping process is presented in Figure 1. Flanking sequences of mapped reads were subjected to secondary structure analysis to predict pre-miRNA sequences using Mfold software. The criteria used for miRNA annotation and hairpin structure determination are presented in Table 1 $[19,20]$.

2.4. Target Prediction for miRNAs and GO Analysis. We compared 1839 ESTs of Chiloscyllium plagiosum with 1344 ESTs with $98 \%$ similarity using the cd-hit-454 program [21, 22]. Ninety-one mature miRNA sequences were used as custom sequences to search ESTs and perform target prediction using the program miRanda v1.0b [23] with the following parameter settings: Gap Open Penalty: -8.0; Gap Extend:-2.0; Score Threshold: 50.0; Energy Threshold: $-20.0 \mathrm{kcal} / \mathrm{mol}$; Scaling Parameter: 2.0. The target sequences were annotated using BLAST to the GO database (http://www.geneontology.org/), thus predicting which processes the miRNAs participate in.

2.5. Stem-Loop RT-PCR. Seven candidate miRNAs were chosen for verification of expression using stem-loop RT-PCR. Four PC miRNAs were randomly selected (PC-3p-186_7748, PC-5p-970_1302, PC-5p-108_13860, and PC-5p-14_74120), 
TABLE 1: Criteria used for miRNAs annotation and hairpin structure determination.

miRNAs annotation

The miR_name is composed of the known miR name in a cluster, an underscore, and a matching annotation such as

$\mathrm{L}-n$ means that the miRNAs_seq (detected) is $n$ base less than known rep_miRSeq in the left side;

$\mathrm{R}-n$ means that the miRNAs_seq (detected) is $n$ base less than known rep_miRSeq in the right side;

$\mathrm{L}+n$ means that the miRNAs_seq (detected) is $n$ base more than known rep_miRSeq in the left side;

$\mathrm{R}+n$ means that the miRNAs_seq (detected) is $n$ base more than known rep_miRSeq in the right side;

2ss5TC13TA means 2 substitutin (ss), which are $\mathrm{T} \rightarrow \mathrm{C}$ at position 5 and $\mathrm{T} \rightarrow \mathrm{A}$ at position 1 .

The miRNAs_seq (detected) is exactly the same as known rep_miRSeq; miRNAs_name is the name of representative miRNAs.

Hairpin determination

Definition of MFEI: MFEI $=-d G * 100 /$ mirLen/CG\%.

Criteria:

(1) free energy $(d G$ in $\mathrm{kCal} / \mathrm{mol}) \leq-15$,

(2) length of hairpin (up and down stem + terminal loop) $\geq 50$,

(3) number of basepairs (bp) in stem region $\geq 16$,

(4) length of terminal loop $\leq 20$,

(5) number of basepairs (bp) in mature or mature $*$ region $\geq 12$,

(6) percentage of small RNA in stem region $(\mathrm{pm}) \geq 80 \%$,

(7) number of allowed errors in mature region $\leq 7$,

(8) number of allowed errors in one bulge in stem $\leq 12$,

(9) number of allowed errors in one bulge in mature region $\leq 8$,

(10) number of allowed biased errors in one bulge in mature region $\leq 4$,

(11) number of allowed biased bulges in mature region $\leq 2$,

(12) $\mathrm{MFEI} \geq 0.7$.

and 3 known miRNAs were also analyzed: fru-miR-204a, hsamiR-142-3p_R-1, and fru-miR-126. Total RNA was extracted using Trizol reagent and reverse transcribed using a Reverse Transcription System (Promega). The $5 \mu \mathrm{L}$ reactions contained $250 \mathrm{ng}$ of RNA sample and $2 \mu \mathrm{M}$ of stem-loop RT primer $(0.5 \mu \mathrm{L})$. The reactions were incubated for $45 \mathrm{~min}$ at $42^{\circ} \mathrm{C}$ and $5 \mathrm{~min}$ at $95^{\circ} \mathrm{C}$ and then held at $4^{\circ} \mathrm{C} .20 \mu \mathrm{L}$ PCR reactions $(2 \times$ Taq PCR Master Mix, Lifefeng) were run using $0.5 \mu \mathrm{L}$ of cDNA product by incubating for $5 \mathrm{~min}$ at $95^{\circ} \mathrm{C}$, followed by 40 cycles of $94^{\circ} \mathrm{C}$ for $30 \mathrm{sec}, 60^{\circ} \mathrm{C}$ for $30 \mathrm{sec}$, and $72^{\circ} \mathrm{C}$ for $30 \mathrm{sec}$. The PCR products were detected with gel electrophoresis. The positive control was 18s rRNA [4]. All of the primers that were used for RT-PCR are listed in Table 2. The reverse primers for PC-3p-186_7748 and fru-miR-204a were miR-Reversel, and fru-miR-126 miRReverse3, respectively, while the remaining 4 miRNAs used miR-Reverse2.

2.6. Real-Time PCR Analysis. According to our literature search, the small RNA sequencing results, miRNA target gene results, and GO analysis, three known miRNAs (hsa-miR142-3p_R-1, xtr-miR-125b, and fru-miR-204) related to liver regeneration and liver diseases were assayed in normal and regenerating liver tissue at $0 \mathrm{~h}, 6 \mathrm{~h}, 12 \mathrm{~h}$, and $24 \mathrm{~h}$ using realtime PCR. A FastStart Universal SYBR Green Master (ROX) fluorescence quantitative PCR reaction kit (Roche) was used, and a $20 \mu \mathrm{L}$ reaction system was designed according to the kit instructions. Each sample was repeated 3 times, and the cycling conditions were as follows: $95^{\circ} \mathrm{C}$ for $2 \mathrm{~min}$ followed by 40 cycles of $95^{\circ} \mathrm{C}$ for $15 \mathrm{~s}$ and $60^{\circ} \mathrm{C}$ for $30 \mathrm{~s}$. A melting curve analysis was used to ensure the specificity of real-time PCR primers.

2.7. DDRT-PCR. The total RNA of normal and regenerating liver tissues at $24 \mathrm{~h}$ was extracted using Trizol and was reverse transcribed using a Reverse Transcription System (Promega). The $25 \mu \mathrm{L}$ reactions contained $1250 \mathrm{ng}$ of RNA and $50 \mu \mathrm{M}$ of anchor primer $(2.5 \mu \mathrm{L})$. The reactions were incubated for $45 \mathrm{~min}$ at $42^{\circ} \mathrm{C}$ and $5 \mathrm{~min}$ at $95^{\circ} \mathrm{C}$ and then held at $4^{\circ} \mathrm{C}$. $10 \mu \mathrm{L}$ PCR reactions ( $2 \times$ Taq PCR Master Mix, Lifefeng) were performed using two anchor primers and twenty random primers. All of the primers used for DDRT-PCR are listed in Table 3. The $10 \mu \mathrm{L}$ reactions contained $5 \mu \mathrm{L}$ of $2 \times$ Taq PCR Master Mix, $0.1 \mu \mathrm{L} 50 \mu \mathrm{mol} / \mathrm{L}$ anchor primer, $0.5 \mu \mathrm{L}$ $10 \mu \mathrm{mol} / \mathrm{L}$ random primer, $0.5 \mu \mathrm{L} \mathrm{cDNA}$, and $3.9 \mu \mathrm{L} \mathrm{ddH}_{2} \mathrm{O}$. The reactions were incubated for $5 \mathrm{~min}$ at $95^{\circ} \mathrm{C}$, followed by 40 cycles of $95^{\circ} \mathrm{C}$ for $30 \mathrm{sec}, 40^{\circ} \mathrm{C}$ for $2 \mathrm{~min}$, and $72^{\circ} \mathrm{C}$ for $1 \mathrm{~min}$. The PCR products were detected by nondenaturing polyacrylamide gel electrophoresis and silver staining.

2.8. Cloning and Sequencing. The target fragments were recovered using the crushing and soaking method. The screened differential genes were used as templates, and the corresponding anchor primers and random primers were 


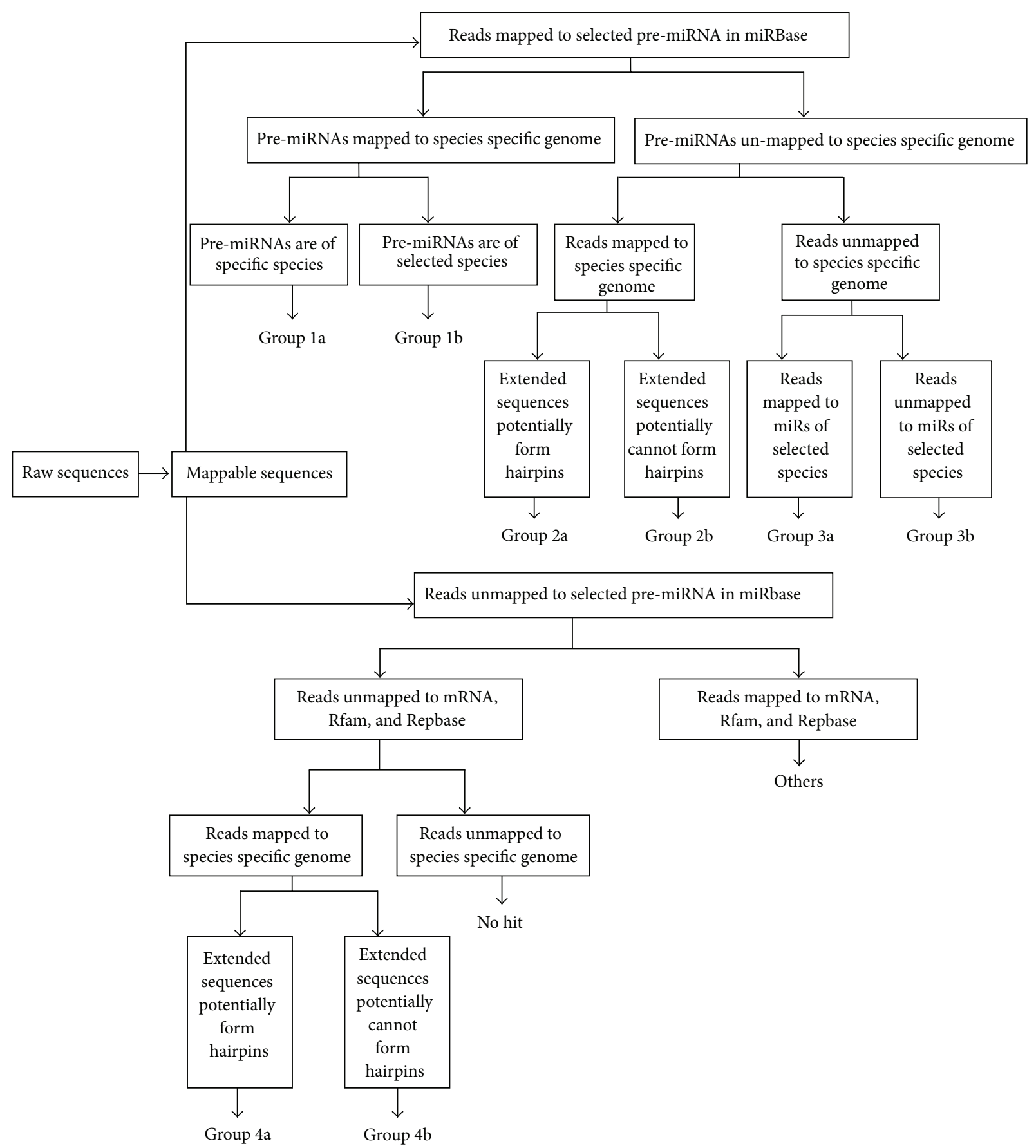

Figure 1: Procedure for mapping reads to database sequences. (1) specific species, that is, Callorhinchus milii; (2) selected species: Fugu rubripes, Oryzias latipes, Xenopus laevis, Xenopus tropicalis, Homo sapiens, and Mus musculus.

used as primers for PCR. The PCR reaction system and procedure were the same as the previous ones. After assaying for and recovering the target differential fragments, they were cloned into the pMD18-T simple vector to construct recombinant plasmids. The differential genes were tested through bacterial PCR. The $10 \mu \mathrm{L}$ reactions contained $5 \mu \mathrm{L}$ $2 \times$ Taq PCR Master Mix, $0.4 \mu \mathrm{L} 10 \mu \mathrm{mol} / \mathrm{L}$ PCR Forward Primer, $0.4 \mu \mathrm{L} 10 \mu \mathrm{mol} / \mathrm{L}$ PCR Reverse Primer, $0.5 \mu \mathrm{L}$ cDNA

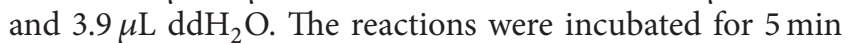
at $95^{\circ} \mathrm{C}$, followed by 40 cycles of $95^{\circ} \mathrm{C}$ for $30 \mathrm{sec}, 40^{\circ} \mathrm{C}$ for
$2 \mathrm{~min}$, and $72^{\circ} \mathrm{C}$ for $1 \mathrm{~min}$. DNA sequencing was performed by Shanghai Sunny Biotechnology Co., Ltd. The obtained target differential genes were matched to NCBI EST library sequences through BLAST.

\section{Results}

3.1. Screening miRNAs in Chiloscyllium plagiosum Liver. Raw reads in which the 3 adapters were not found and those with fewer than 15 bases after the 3 adapters were deleted; 
TABLE 2: Primers used in RT-PCR experiment.

\begin{tabular}{|c|c|}
\hline Gene & Primer \\
\hline PC-3p-186_7748-RT & $\begin{array}{l}5^{\prime} \text {-GTCGTATCCAGTGCAGGGTCCGAG } \\
\text { GTATTCGCACTGGATACGACATAGGC-3' }\end{array}$ \\
\hline PC-5p-108_13860-RT & $\begin{array}{l}5^{\prime} \text {-CTCAACTGGTGTCGTGGAGTCGGC } \\
\text { AATTCAGTTGAGAGCTTT-3' }\end{array}$ \\
\hline PC-5p-14_74120-RT & $\begin{array}{l}5^{\prime} \text {-CTCAACTGGTGTCGTGGAGTCGGCA } \\
\text { ATTCAGTTGAGATTCTC-3' }\end{array}$ \\
\hline PC-5p-970_1302-RT & $\begin{array}{l}5^{\prime} \text {-CTCAACTGGTGTCGTGGAGTCGGCAA } \\
\text { TTCAGTTGAGGGACAT- } 3^{\prime}\end{array}$ \\
\hline hsa-miR-142-3p_R-1-RT & $\begin{array}{l}5^{\prime} \text {-CTCAACTGGTGTCGTGGAGTCGGCA } \\
\text { ATTCAGTTGAGCCATAA-3' }\end{array}$ \\
\hline fru-miR-126-RT & $5^{\prime}$-CTCAACTGAATTGCCGACTCCACGACACCAGTTGAGGCATTA-3' \\
\hline fru-miR-204-RT & $\begin{array}{l}5^{\prime} \text {-GTCGTATCCAGTGCAGGGTCCGAGG } \\
\text { TATTCGCACTGGATACGACATGCCT- } 3^{\prime}\end{array}$ \\
\hline PC-3p-186_7748-Forward & $5^{\prime}$-GCACTTGTCCCAGCCTATGTC-3' \\
\hline PC-5p-108_13860-Forward & $5^{\prime}$-CCGTGTAAACATCTGTAACTGAAAG-3' \\
\hline PC-5p-14_74120-Forward & $5^{\prime}$-GCGAGCACTGTCTAACCTGAG-3' \\
\hline PC-5p-970_1302-Forward & $5^{\prime}$-GGTCCAACCTCTTATGTCCСТC-3' \\
\hline hsa-miR-142-3p_R-1-Forward & $5^{\prime}$-GGCTTTAGTGTTTCCTACTTTATGG-3' \\
\hline fru-miR-126-Forward & $5^{\prime}$-TCCTACCGTGAGTAATAATGCC-3' \\
\hline fru-miR-204-Forward & $5^{\prime}$-CGTGTTCCCTTTGTCATCCTATC-3' \\
\hline 18s rRNA-Forward & $5^{\prime}$-GACTCAACACGGGAAACCTCA- $3^{\prime}$ \\
\hline 18s rRNA-Reverse & $5^{\prime}$-CAGACAAATCGCTCCACCAA- $3^{\prime}$ \\
\hline miR-Reversel & $5^{\prime}$-AGCAGGGTCCGAGGTATTC-3' \\
\hline miR-Reverse2 & $5^{\prime}$-GTGTCGTGGAGTCGGCAAT-3' \\
\hline miR-Reverse 3 & $5^{\prime}$-AACTGAATTGCCGACTCCAC-3' \\
\hline
\end{tabular}

TABLE 3: The primers of DDRT-PCR.

\begin{tabular}{|c|c|c|c|}
\hline Primer & Sequence & Primer & Sequence \\
\hline Anchor primer 1 & $5^{\prime}$-AGCTTTTTTTTTTTVA-3' & Anchor primer 2 & $5^{\prime}$-AGCTTTTTTTTTTTVC-3' \\
\hline Random primer 1 & $5^{\prime}$-GCTAACGATG-3’ & Random primer 2 & $5^{\prime}$-TGGATTGGTC-3' \\
\hline Random primer 3 & $5^{\prime}$-CTTTCTACCG-3' & Random primer 4 & $5^{\prime}$-TTTTGGCTCC- $3^{\prime}$ \\
\hline Random primer 5 & $5^{\prime}$-GGAACCAATG-3' & Random primer 6 & $5^{\prime}$-AAACTCCGTC-3' \\
\hline Random primer 7 & $5^{\prime}$-TCGATACAGG-3' & Random primer 8 & $5^{\prime}$-TGGTAAAGGG-3' \\
\hline Random primer 9 & $5^{\prime}$-TCGGTCATAG- $3^{\prime}$ & Random primer 10 & $5^{\prime}$-CTGCTTGATG-3' \\
\hline Random primer 11 & $5^{\prime}$-TACCTAAGCG-3' & Random primer 12 & $5^{\prime}$-CTGCTTGATG-3' \\
\hline Random primer 13 & $5^{\prime}$-GTTTTCGCAG-3' & Random primer 14 & $5^{\prime}$-GATCAAGTCC- $3^{\prime}$ \\
\hline Random primer 15 & $5^{\prime}$-GATCCAGTAC- $3^{\prime}$ & Random primer 16 & $5^{\prime}$-GCTCACGTAG-3' \\
\hline Random primer 17 & $5^{\prime}$-GATCTGACAC-3' & Random primer 18 & $5^{\prime}$-GCTATCAGAC-3' \\
\hline Random primer 19 & $5^{\prime}$-GATCATAGCG- $3^{\prime}$ & Random primer 20 & $5^{\prime}$-GATCAATCGC-3' \\
\hline
\end{tabular}

junk reads were removed. Following these changes, 15,361,801 and 10,146,583 reads remained in the Chiloscyllium plagiosum normal and regenerating livers at $0 \mathrm{~h}$ and $24 \mathrm{~h}$ after $\mathrm{PH}$. The length distribution of the small RNA reads ranged from 15 to $30 \mathrm{nt}$ (Figure 2). Through mapping analysis, 15,361,801 and $10,146,583$ reads could be distributed into the groups that are presented in Table 4.

Two hundred and fifty-seven miRNAs were identified in Chiloscyllium plagiosum, including 91 known miRNAs and 166 Chiloscyllium plagiosum putative candidate (PC) miRNAs. In addition, 31 PC miRNAs were found only in $24 \mathrm{~h}$ (after PH) regenerative liver tissue, and $49 \mathrm{PC}$ miRNAs were found only in normal liver tissue. A total of 76 unique miRNA reads were mapped to the pre-miRNAs of selected species in the miRBase, and these pre-miRNAs were further mapped to the Callorhinchus milii genome (group 1b). Additionally, 15 miRNA reads mapped to premiRNAs of the selected species but not to the Callorhinchus milii genome. These 15 miRNA reads were mappable to the Callorhinchus milii genome, and the extended sequences could potentially form hairpins (group 2a). Additional 166 PC miRNAs that were identified did not map to any 
TABLE 4: Distribution of small RNA among LN and LR24.

\begin{tabular}{lcccc}
\hline Category & Total RNAs in LN & Percent & Total RNAs in LR24 & Percent \\
\hline Total small RNAs & 15361801 & $100 \%$ & 10146583 & 0 \\
Group la & 0 & $0.00 \%$ & 985411 & $0.00 \%$ \\
Group 1b & 1600835 & $10.40 \%$ & 39787 & $9.70 \%$ \\
Group 2a & 56020 & $0.40 \%$ & 12569 & $0.40 \%$ \\
Group 2b & 25388 & $0.20 \%$ & 1113914 & $0.10 \%$ \\
Group 3a & 2300528 & $15.00 \%$ & 40956 & $11.00 \%$ \\
Group 3b & 72334 & $0.50 \%$ & 153216 & $0.40 \%$ \\
Group 4a & 310150 & $2.00 \%$ & 195545 & $1.50 \%$ \\
Group 4b & 301238 & $2.00 \%$ & 4341986 & $320 \%$ \\
Group 5 & 6032607 & $39.30 \%$ & 3263199 \\
Group 6 & 4662701 & $30.40 \%$ & $32.80 \%$ \\
\hline
\end{tabular}

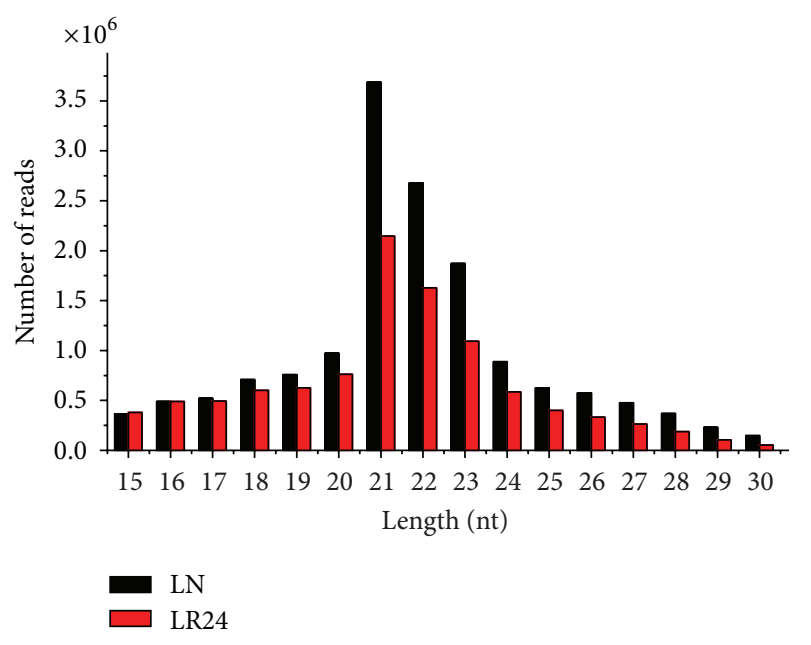

FIGURE 2: Length distribution of small 15-to-30 nucleotide RNAs in LN and LR24. The nucleotide (nt) lengths of the reads are indicated on the $x$-axis, and the number of total reads are indicated on the $y$-axis.

known pre-miRNAs, either in the mRNA, Rfam, or Repbase databases. These reads could map to the Callorhinchus milii genome, however, and exhibited the potential to form hairpin structures (group 4a). The predicted stem-loop secondary structures of 5 pre-miRNAs (fru-miR-126, hsamiR-142-3p_R-1, ola-miR-1388-3p_R+5/ola-miR-1388-5p_R1, PC-5p-14_74120/PC-3p-525510_1, and fru-miR-204a) from the Mfold database are presented in Figure 3. Information about all of these miRNAs is presented in supplementary Table 1; see in Supplementary Material available online at http://dx.doi.org/10.1155/2013/795676.

3.2. The Expression of Chiloscyllium plagiosum miRNAs. The average number of reads of known miRNAs in normal and regenerating liver tissues was 8173 and 8972 , respectively. The average reads of PC miRNAs were 1687 and 1781, respectively. One hundred twenty-eight PC miRNA reads were less than $10 \mathrm{nt}$, which is consistent with a previous observation that nonconserved miRNAs are generally expressed at lower levels and represent tissue- or development-specific expression patterns [24]. $\log _{2}$ ratios of 116 miRNAs reads in regenerating and normal tissues were larger than 1 , of which only 5 miRNAs reads were more than $10 \mathrm{nt}$, and only 8 known miRNAs were included. Therefore, both miRNA expression type and abundance have no obvious differences during liver regeneration from $0 \mathrm{~h}$ to $24 \mathrm{~h}$.

Moreover, miRNAs are often present in the genome in clusters, where several miRNAs are aligned in the same orientation and transcribed as a polycistronic message, allowing them to act cooperatively. Based on miRBase's definition of a miRNA cluster $(10,000 \mathrm{bp})$, we discovered a total of 34 clusters in the Callorhinchus milii genome, of which 16 clusters were generated from the 16 pre-miRNAs, and 2 mature miRNAs were cleaved from each pre-miRNA (Supplementary Table 2). The largest cluster (no. 27) contained six miRNAs.

3.3. Target Predictions for miRNAs and GO Analysis. miRNAs are involved in a wide variety of biological processes by binding target sites with seed sequences $[25,26]$. Identifying the total number of target sites, especially for those lowabundance and species-specific miRNAs, is helpful for appreciating the breadth of miRNA functions [27]. We calculated the potential binding sites between miRNAs and the ESTs of Chiloscyllium plagiosum with miRanda to determine the potential genes targeted by miRNAs. Of 91 known miRNAs, 86 miRNAs had targeted genes; most miRNAs have more than one, and 144 miRNAs had multiple predicted target sites. Most predicted targeted genes may be regulated by more than one miRNA.

The functional classification for targeted genes was analyzed using Gene Ontology analysis. The targets that were functionally annotated in the GO database could be divided to 38 subclasses, presented in Figure 4. Forty-six miRNAs were related to cell proliferation and growth terms (Supplementary Table 3), including the following miRNAs: xtr-miR34a_R-1 [28], fru-miR-122_R+1 [29], fru-miR-27b_R-1 [30], fru-miR-181b_R+1 [31], fru-miR-23b_R-1 [32], ola-miR-144_L$1 \mathrm{R}+2$ _1ss12TA [33], ola-miR-103_R+2 [29], and fru-miR-26 [34]. Based on comprehensive consideration of our literature search, the small RNA sequencing results, miRNA target gene results, and GO analysis, three known miRNAs (hsa-miR142-3p_R-1, xtr-miR-125b, and fru-miR-204) related to liver 


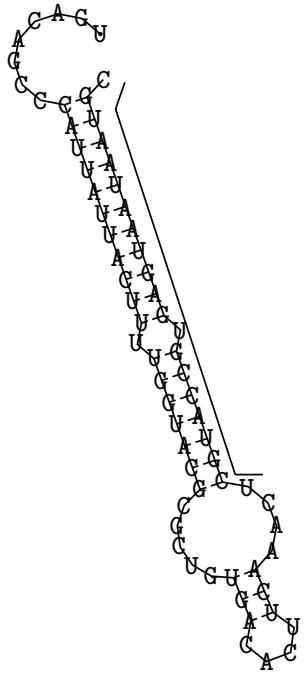

(a)

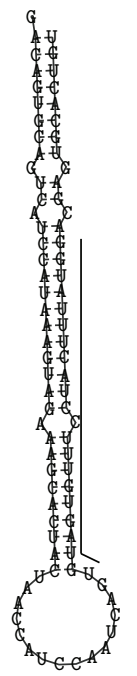

(b)

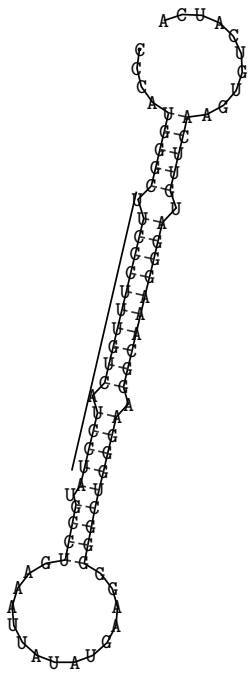

(c)

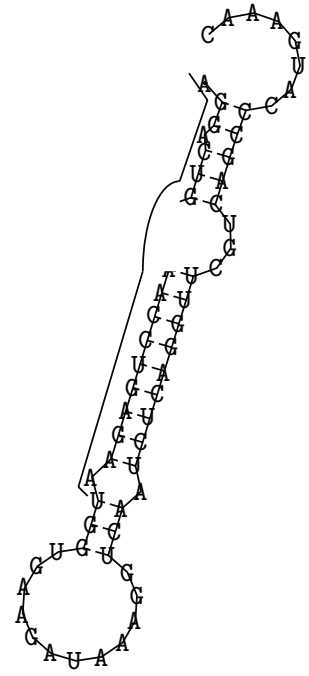

(d)

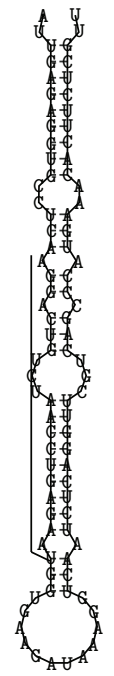

(e)

FIGURE 3: Secondary structures of 5 pre-miRNAs. (a) fru-miR-126, (b) hsa-miR-142-3p_R-1, (c) fru-miR-204a, (d) ola-miR-1388-3p_R+5/olamiR-1388-5p_R-1, (e) PC-5p-14_74120/PC-3p-525510_1. The underlined letters refer to the candidate miRNA sequences. For (d) and (e), the underlined letters refer to the $5 \mathrm{p}$ miRNAs, and the upper-case letters refer to the $3 \mathrm{p}$ miRNA sequences.

regeneration and liver diseases were screened to the following experiments, and the potential binding sites between miRNAs and the ESTs of Chiloscyllium plagiosum with miRanda were presented in Figure 5.

\subsection{Real-Time PCR Analysis of the miRNAs of Different Liver} Regenerative Stages. Seven candidate miRNAs were selected for expression-level confirmation using stem-loop RT-PCR. Figure 6 shows that all of the 7 predicted miRNAs were expressed in the Chiloscyllium plagiosum liver. With 18s rRNA as positive control, the expression of three target miRNAs was normalized and used to analyze the expression of the miRNA at different liver regenerative stages. Figure 7 indicates that there is a large transcriptional difference between three known miRNAs at different stages of liver regeneration. Significant miRNA expression was observed in regenerating liver tissues at $6 \mathrm{~h}$ and $12 \mathrm{~h}$. The expression level of xtr-miR$125 \mathrm{~b}$ was the highest in regenerating liver tissues at $6 \mathrm{~h}$ and was 40 times higher than that in normal liver tissue. Levels of fru-miR-204, xtr-miR-125b, and has-miR-142-3p_R-1 in regenerating liver tissues at $24 \mathrm{~h}$ were $0.685,0.86$, and 1.586 times higher than those in normal liver tissue, respectively (Table 5). This result is consistent with the sequencing data.

3.5. Differential Gene Sequence Analysis. Forty pairs of PCR product results were analyzed by $5 \%$ polyacrylamide gel electrophoresis and silver staining, and the bands were clear. Six pairs of PCR products are presented in Figure 8, of which two obvious differential bands showed higher expression in regenerating liver. Overall, ten differential sequences were obtained through differential display analysis.

These ten differential sequences were run through BLAST. Three sequences exhibited high similarity to NCBI EST library sequences, and the other 7 sequences had no homology to any known genes. The homology of RF1-61 with
33 Chiloscyllium griseum cDNA clone sequences was up to $100 \%$. The homology of NF2-2 with 2 cloudy catshark embryo cDNA library sequences was higher than $80 \%$. The homology of RF2-6s with dogfish shark stem cell line sequences was $88 \%$. The matching and differential expression results are presented in Table 6 and consist of 8 sequences ranging from 100 to $500 \mathrm{bp}$. Three sequences showed high similarity to NCBI EST library sequences through BLAST; 5 sequences were overexpressed, and another five were downregulated during liver regeneration.

\section{Discussions}

The emergence of high-throughput sequencing technology has greatly hastened the discovery of small expressed RNAs in newly analyzed and rare species. Because of the high sequence homology between miRNAs from related species and the stem-loop structure of their precursor sequences, miRNA precursor sequences can be used to perform homology screens covering the entire genome of species. These target gene sequences can be identified using RNA secondary structure analysis software (e.g., RNAfold, MirScan, and MFold) combined with dynamic analysis [35]. A combination of deep sequencing and bioinformatics analysis allows for the identification of new and rarely expressed nonconserved miRNAs, especially in less frequently studied species [36, 37].

Here, we report the first complete analysis of miRNA populations in the Chiloscyllium plagiosum liver using deep sequencing and bioinformatics analysis. Due to the high conservation of miRNAs between related species, we selected pre-miRNAs/miRNAs of Danio rerio, Fugu rubripes, Oryzias latipes, Xenopus laevis, Xenopus tropicalis, Homo sapiens, and Mus musculus to map the reads. In the present study, $257 \mathrm{miR}-$ NAs were identified, of which 166 were specific to Chiloscyllium plagiosum. These results indicate that the method was 

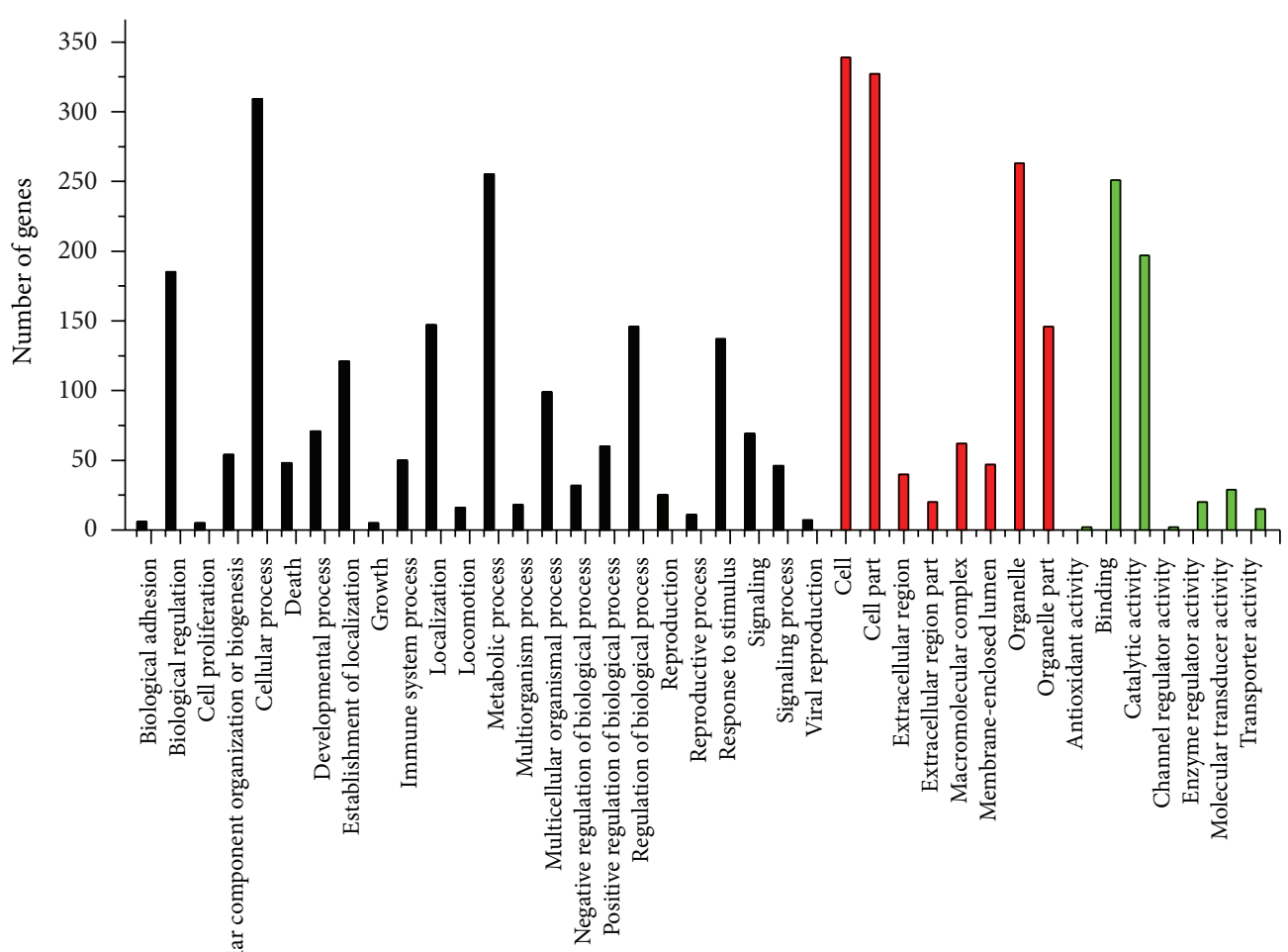

Annotation class

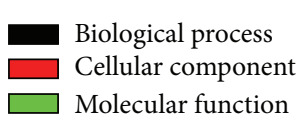

FIGURE 4: GO analysis of targeted genes. The classes are shown on the $x$-axis; the number of genes for each class is shown on the $y$-axis. The number of genes for the three classes-biological process, cellular component, and molecular function-is 687, 608, and 612, respectively.

$$
\begin{gathered}
\text { Query: }{ }^{\prime} \text { TCCGTATCCTACTGTTTCCCTT } 5^{\prime} \\
\||||=||||||||||||| \\
\text { Ref: } 5{ }^{\prime} \text { AGTCAGGGAGAGACAGAGGGA } 3^{\prime} \\
\text { Energy: }-20.100000 \mathrm{kCal} / \mathrm{Mol}
\end{gathered}
$$

(a)
Query: $3^{\prime}$ TCCGTATCCTACTGTTTCCCTT $5^{\prime}$
\[ ||:||:|||||||||| \]
Ref: $5^{\prime}$ ATTCAGGGGGG--AGGGGGA $3^{\prime}$
Energy: $-24.790001 \mathrm{kCal} / \mathrm{Mol}$

(b)

Query: $3^{\prime}$ GGTATT-TCATCC---TTTGTGATGT $5{ }^{\prime}$ $:|||:|||||:|| \quad||||||||||$ Ref: $5^{\prime}$ TCATGACAGTGGGTTTAAGTACTGCA $3{ }^{\prime}$ Energy: $-20.320000 \mathrm{kCal} / \mathrm{Mol}$

(d)

\begin{tabular}{|c|c|c|c|c|c|c|c|c|}
\hline \multirow{2}{*}{ Gene } & \multicolumn{4}{|c|}{ Average $C_{t}$ value \pm standard error } & \multicolumn{4}{|c|}{$2^{-\Delta \Delta C_{t}}$} \\
\hline & LN & LR6 & LR12 & LR24 & LN & LR6 & LR12 & LR24 \\
\hline 18S rRNA & $21.982 \pm 0.116$ & $21.982 \pm 0.116$ & $23.160 \pm 0.016$ & $23.267 \pm 0.127$ & 1.000 & 1.000 & 1.000 & 1.000 \\
\hline xtr-miR-125b & $25.710 \pm 0.141$ & $25.710 \pm 0.141$ & $22.637 \pm 0.354$ & $26.400 \pm 0.222$ & 1.000 & 43.070 & 3.676 & 0.860 \\
\hline has-miR-142-3p_R-1 & $21.035 \pm 0.265$ & $21.035 \pm 0.265$ & $21.126 \pm 0.239$ & $21.395 \pm 0.202$ & 1.000 & 4.803 & 4.623 & 1.586 \\
\hline fru-miR-204a & $18.316 \pm 0.383$ & $18.316 \pm 0.383$ & $18.598 \pm 0.122$ & $19.730 \pm 0.135$ & 1.000 & 4.209 & 2.226 & 0.685 \\
\hline
\end{tabular}

FIGURE 5: The potential binding sites between miRNAs and the ESTs of Chiloscyllium plagiosum. Query represents the miRNAs sequence, and Ref represents their predicted targets. (a) fru-miR-204; (b) fru-miR-204; (c) xtr-miR-125b; (d): has-miR-142-3p_R-1.

TABLE 5: Relative quantitative data analysis of miRNA in four periods regenerative liver tissues. 


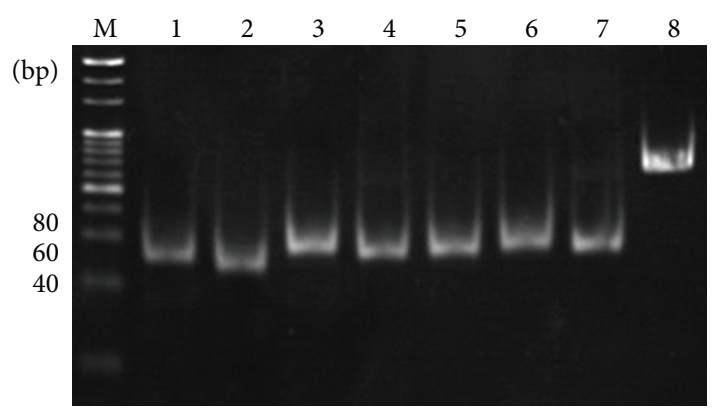

FIgURE 6: The identification of 7 miRNAs by stem-loop RT-PCR. The mRNA expression of 7 miRNAs was confirmed. The sizes of the PCR products were approximately $55 \mathrm{bp}$. 18s rRNA was used as a positive control. M: 20 bp DNA ladder maker; 1-12: PC-3p-186_7748, PC-5p-970_1302, PC-5p-108_13860, PC-5p-14_74120, hsa-miR-1423p_R-1, fru-miR-204, fru-miR-126, 18s rRNA.

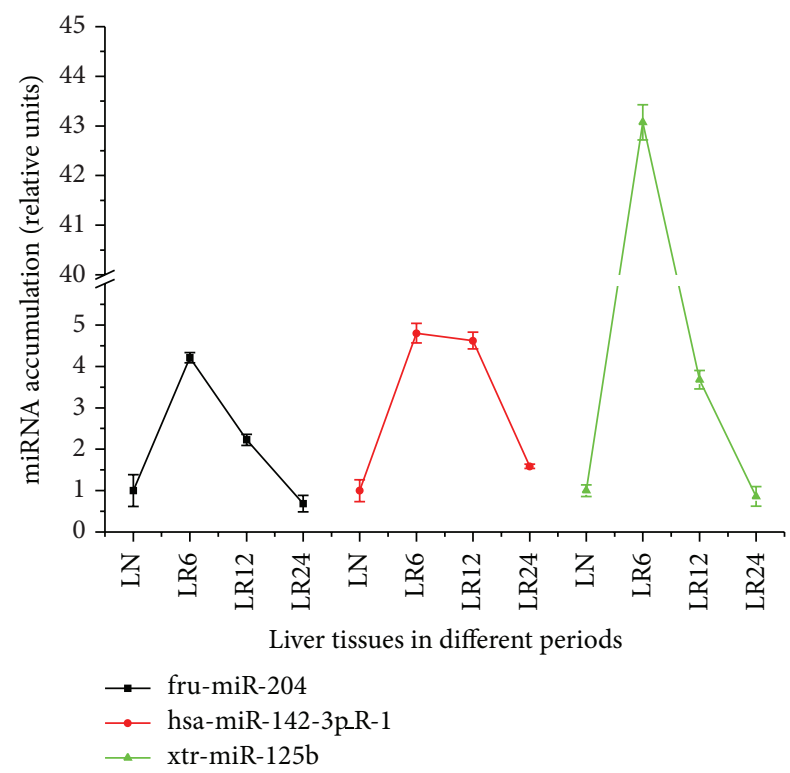

FIGURE 7: Relative expression changes of miRNAs in four periods of liver regeneration. The Real-time PCR results were processed by Microsoft Office Excel, and $2^{-\Delta \Delta C_{t}}$ was used to represent the miRNA differential expression. $\Delta C_{t}=C_{t}$ (target gene) $-C_{t}$ (reference gene) $\Delta \Delta C_{t}=C_{t}$ (experiment group) $-C_{t}$ (control group). the live issues in different periods are indicated on the $x$-axis, and the value of $2^{-\Delta \Delta C_{t}}$ showed in Table 5 are indicated on the $y$-axis.

effective for identifying low-abundance and species-specific small RNAs. Comparative analysis of the $C$. milii genome with the whole-genome assemblies of Danio rerio, Fugu rubripes, and Homo sapiens suggested that (i) noncoding sequences in Callorhinchus milii are evolving more slowly than in teleost fishes and that (ii) the Callorhinchus milii genome has experienced fewer chromosomal rearrangements compared with teleost fish genomes. Although cartilaginous fish diverged from the human lineage before teleost fish, a higher proportion of regulatory elements are conserved between cartilaginous fish and humans than between teleost fish and humans $[16,38]$. Based on conclusions that were drawn from miRNA analysis, our research conclusively demonstrated that
TABLE 6: Analysis of differential expressed sequences.

\begin{tabular}{lccc}
\hline Clone & Length (bp) & Query coverage & Max identity to the EST \\
\hline RF1-61 & 534 & $11 \%$ & $100 \%$ \\
RF1-6s & 258 & & novel \\
RF2-8 & 283 & & novel \\
NF2-2 & 173 & $94 \%$ & $80+\%$ \\
NF1-7 & 236 & & novel \\
NF1-19 & 326 & & novel \\
RF2-6s & 244 & $78 \%$ & $88 \%$ \\
RF2-61 & 278 & & novel \\
NF2-19 & 77 & & novel \\
NF1-9 & 208 & & novel \\
\hline
\end{tabular}

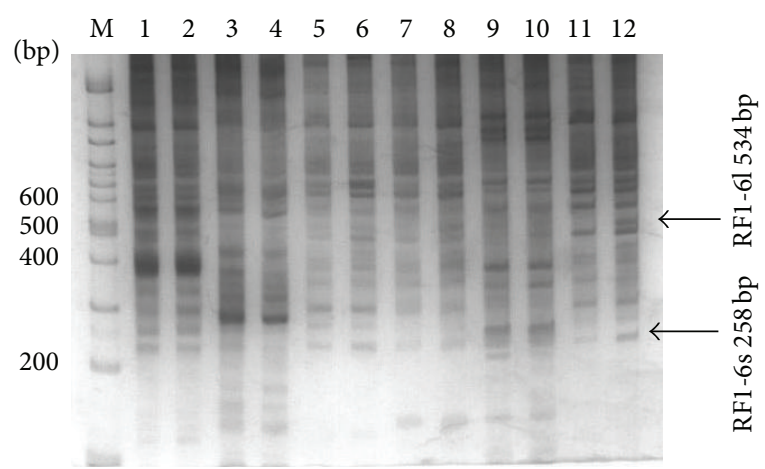

FIgURE 8: Results of DDRT-PCR. M: 100 bp DNA ladder marker; Lanes 1-12: NF1-1, RF1-1, NF1-2, RF1-2, NF1-3, RF1-3, NF1-4, RF1-4, NF1-5, RF1-5, NF1-6, RF1-6.

cartilaginous and teleost fishes may not have as close a genetic relationship as previously thought.

In the present study, we observed that the frequency of most PC miRNAs was extremely low. This observation is in accordance with the low expression observed for nonconservative miRNAs and for those involved in organizational or special development periods. Moreover, miRNA genes often form clusters in the genome. Certain miRNAs in genes clusters share the same set of control sequences and are found on the same transcript, whereas some miRNAs in gene clusters are transcribed from independent transcripts, such as miR-433 and miR-127 [39]. An miRNA gene can produce two different miRNAs through duplex transcription and thus control different target genes [40]. A total of 34 miRNA gene clusters were identified in this study, of which 16 produced 32 miRNA groups through duplex transcription. Each of these duplex groups produced 2 miRNAs. This finding provides important clues for probing the function of these miRNAs in future research.

Through miRNA target prediction and GO analysis, we focused on the relation between miRNAs and their targets, thus focusing on mechanisms that involved cell proliferation, immune system processes, and other biological functions. However, as the genome of Chiloscyllium plagiosum is not fully sequenced and annotated, it was difficult to determine whether these miRNA targets have any functional bias. 
It should be noted that many targets could not be annotated in the GO database due to their low homology to orthologs; thus, the miRNA-target network is likely more complex than the results presented here. MiRNA target genes were mostly predicted through bioinformatics software, and miRNA binding sites in most species are in $3^{\prime}$-untranslated regions of the target gene. However, it has been reported that siRNA-mediated translational inhibition can be induced by an incomplete complementary site in the ORF region of a mammalian reporter gene, which means that the target sequence of a given miRNA is not only in the $3^{\prime}$-untranslated region. Because the miRNA and genome of Chiloscyllium plagiosum have not been reported and the NCBI database includes just 33 mRNAs, the ESTs and these 33 mRNAs of Chiloscyllium plagiosum were used to predict miRNA target genes. The target genes should also be tested using a dual luciferase reporter gene assay system, western blot, or some other experimental method. Through target predictions for miRNAs and GO analysis, we can predict that the target genes are related to thirty-eight biological functions related to "molecular function," "cellular component," or "biological process." A total of 46 related miRNA were screened for cell proliferation and growth, and only eight miRNA have been reported in liver regeneration contexts. Our results will greatly promote research about liver regeneration mechanisms related to miRNA.

Liver regeneration involves regulation of cell proliferation, including such processes as G0/G1 and G1/S transitions of the cell cycle and cell division. Differential expression levels of three miRNAs related to cell proliferation and apoptosis were tested in regenerating liver tissues at $0 \mathrm{~h}, 6 \mathrm{~h}, 12 \mathrm{~h}$, and $24 \mathrm{~h}$ through the real-time PCR. We determined that three target miRNAs (hsa-miR-142-3p_R-1, xtr-miR-125b, and fru-miR-204) exhibited great differential transcription in regenerating liver tissues at $0 \mathrm{~h}, 6 \mathrm{~h}, 12 \mathrm{~h}$, and $24 \mathrm{~h}$ with higher expression in the early timepoints of liver regeneration. Expression of miRNAs showed a rising trend in regenerating liver tissues at $6 \mathrm{~h}, 12 \mathrm{~h}$ but in the later timepoints presented a downward trend, with normal levels in regenerating liver tissues at $24 \mathrm{~h}$. It has been reported that apoptotic activity increases significantly in the early timepoints $(0-6 \mathrm{~h})$ and late timepoints $(4-7 \mathrm{~d})$ of liver regeneration. Therefore, we can speculate that the expression of these three miRNAs increased significantly in the start-up stage of liver regeneration. These miRNAs may be relevant to the inhibition of cell proliferation and DNA synthesis. After $24 \mathrm{~h}$, expression decreased to normal. This may be relevant to the $S$ stage of DNA synthesis, which peaks at this time. In addition, it has been reported that the expression of miRNA showed a rising trend in regenerating liver tissues of ratsat $3 \mathrm{~h}, 12 \mathrm{~h}$, and $18 \mathrm{~h}$ after two-thirds $\mathrm{PH}$, and expression of $70 \%$ of miRNAs showed a downward trend in regenerating rat livers $24 \mathrm{~h}$ after two-thirds $\mathrm{PH}$. Expression of genes relevant to miRNA generation began to decrease 18-36 h after $\mathrm{PH}$, most obviously $24 \mathrm{~h}$ after $\mathrm{PH}$, including RNasen, Dgcr8, Dicer, Tarbp2, and ect [41]. Therefore, we can speculate that this upregulation followed by downregulation of expression may be induced by a negative feedback mechanism involving miRNA generation. It has been reported that miR-142-3p controls the target gene RAC1 and inhibits liver cancer cell proliferation and invasion [42], that miR-204a negatively controls the target gene $\mathrm{Bcl}-2$ to promote apoptosis [43], and that miR-125b was upregulated in Taxol-resistant cells, causing a marked inhibition of Taxol-induced cytotoxicity and apoptosis and a subsequent increase in the resistance to Taxol in cancer cells [44]. Therefore, combining the reported references on miRNAs in liver regeneration and the related signal transduction network references may be helpful to screen and test the liver regeneration miRNAs and their target genes. Researching mechanisms such as when and how the interactions between miRNAs and target genes occur will deepen the understanding of miRNA regulation in the injured liver.

\section{Conclusions}

This study provides the first large-scale identification and characterization of Chiloscyllium plagiosum miRNAs, adds a significant number of novel miRNA sequences to the currently available database, and lays the foundation for further understanding of miRNA function in the regulation of Chiloscyllium plagiosum liver development. However, considerable work remains to confirm the identity of these miRNAs and their functional significance. Despite the conservation of miRNAs, it is likely that we overlooked several Chiloscyllium plagiosum specific miRNAs due to the unavailability of genome sequences for this species. Moreover, the expressed population of miRNAs can change in different tissues and at different development stages. The identified miRNAs may not represent all of the miRNAs that exist in Chiloscyllium plagiosum, and more research is required to acquire a full set of miRNAs for this species.

\section{Acknowledgments}

The authors thank LC-Bio (Hangzhou, China) for performing the Illumina sequencing. The authors also thank Qingtuo Guo and Lufeng Li for their assistance during the analysis and interpretation of data. They also thank Elsevier Language Editing for editing the language of this paper. This work was supported by financial grants from the National High Technology Research and Development Program (no. 2012ZX09102301-009), the National High Technology Research and Development Program (no. 2011AA100603), National Natural Science Foundation of China (No. 11105121), National Basic Research Program of China (no. 2012CB114600), Science Technology Department of Zhejiang Province (no. 2012C 22053), Zhejiang Natural Science Foundation (no. Y3110051), Science Technology Department of Zhejiang Province Project (no. 2012C22053), Financial grants from Zhejiang Sci-Tech University (no. 1016848-Y).

\section{References}

[1] S. Kumar and S. B. Hedges, "A molecular timescale for vertebrate evolution," Nature, vol. 392, no. 6679, pp. 917-920, 1998.

[2] B. Venkatesh, E. F. Kirkness, Y.-H. Loh et al., "Survey sequencing and comparative analysis of the elephant shark (callorhinchus milii) genome," PLoS Biology, vol. 5, no. 4, article e101, 2007. 
[3] F. J. Huang and W. T. Wu, "Purification and characterization of a new peptide (S-8300) from shark liver," Journal of Food Biochemistry, vol. 34, no. 5, pp. 962-970, 2010.

[4] F. Zhou, Y. Wang, Y. Guan et al., "Construction and characterization of a cDNA library from shark regenerated hepatic tissue," Fish and Shellfish Immunology, vol. 30, no. 4-5, pp. 1170-1177, 2011.

[5] X. Zongfa, C. Guangming, H. Ying et al., "Study on immune activity of shark liver extracts," Chinese Journal of Biochemical Pharmaceutics, vol. 3, 1999.

[6] Q. Ma, Y. Q. Su, J. Wang, Z. M. Zhuang, and Q. S. Tang, "Molecular cloning and expression analysis of major histocompatibility complex class IIB gene of the Whitespotted bambooshark (Chiloscyllium plagiosum)," Fish Physiology and Biochemistry, vol. 39, no. 2, pp. 131-142, 2012.

[7] A. Grishok, A. E. Pasquinelli, D. Conte et al., "Genes and mechanisms related to RNA interference regulate expression of the small temporal RNAs that control C. elegans developmental timing," Cell, vol. 106, no. 1, pp. 23-34, 2001.

[8] G. Hutvágner and P. D. Zamore, "A microRNA in a multipleturnover RNAi enzyme complex," Science, vol. 297, no. 5589, pp. 2056-2060, 2002.

[9] V. N. Kim, J. Han, and M. C. Siomi, "Biogenesis of small RNAs in animals," Nature Reviews Molecular Cell Biology, vol. 10, no. 2, pp. 126-139, 2009.

[10] Y. Miyazaki, H. Adachi, M. Katsuno et al., "Viral delivery of miR-196a ameliorates the SBMA phenotype via the silencing of CELF2," Nature Medicine, vol. 18, no. 7, pp. 1136-1141, 2012.

[11] Z. G. Cai, S. M. Zhang, Y. Zhang, Y.-Y. Zhou, H. B. Wu, and $\mathrm{X}$. P. Xu, "MicroRNAs are dynamically regulated and play an important role in LPS-induced lung injury," Canadian Journal of Physiology and Pharmacology, vol. 90, no. 1, pp. 37-43, 2012.

[12] S. Subramanian and C. J. Steer, "MicroRNAs as gatekeepers of apoptosis," Journal of Cellular Physiology, vol. 223, no. 2, pp. 289-298, 2010.

[13] S. Bala and G. Szabo, "MicroRNA signature in alcoholic liver disease," International Journal of Hepatology, vol. 2012, Article ID 498232, 6 pages, 2012.

[14] X. Chen, M. Murad, Y. Y. Cui et al., "MiRNA regulation of liver growth after $50 \%$ partial hepatectomy and small size grafts in rats," Transplantation, vol. 91, no. 3, pp. 293-299, 2011.

[15] S. K. Venugopal, J. Jiang, T.-H. Kim et al., "Liver fibrosis causes downregulation of miRNA-150 and miRNA-194 in hepatic stellate cells, and their overexpression causes decreased stellate cell activation," American Journal of Physiology, vol. 298, no. 1, pp. G101-G106, 2010.

[16] B. Venkatesh, A. Tay, N. Dandona, J. G. Patil, and S. Brenner, "A compact cartilaginous fish model genome," Current Biology, vol. 15, no. 3, pp. R82-R83, 2005.

[17] M. Li, Y. Xia, Y. Gu et al., "MicroRNAome of porcine pre- and postnatal development," PLoS ONE, vol. 5, no. 7, article el1541, 2010.

[18] Z. Wei, X. Liu, T. Feng, and Y. Chang, "Novel and conserved micrornas in dalian purple urchin (Strongylocentrotus nudus) identified by next generation sequencing," International Journal of Biological Sciences, vol. 7, no. 2, pp. 180-192, 2011.

[19] S. Ambady, Z. Wu, and T. Dominko, "Identification of novel micrornas in Xenopus laevis metaphase ii arrested eggs," Genesis, vol. 50, no. 3, pp. 286-299, 2012.

[20] B. H. Zhang, X. P. Pan, S. B. Cox, G. P. Cobb, and T. A. Anderson, "Evidence that miRNAs are different from other RNAs," Cellular and Molecular Life Sciences, vol. 63, no. 2, pp. 246-254, 2006.
[21] B. Niu, L. Fu, S. Sun, and W. Li, "Artificial and natural duplicates in pyrosequencing reads of metagenomic data," BMC Bioinformatics, vol. 11, article 187, 2010.

[22] Y. Huang, B. Niu, Y. Gao, L. Fu, and W. Li, "CD-HIT suite: a web server for clustering and comparing biological sequences," Bioinformatics, vol. 26, no. 5, pp. 680-682, 2010.

[23] A. J. Enright, B. John, U. Gaul, T. Tuschl, C. Sander, and D. S. Marks, "MicroRNA targets in Drosophila," Genome Biology, vol. 5, no. 1, 1 page, 2003.

[24] C. Z. Zhao, H. Xia, T. P. Frazier et al., "Deep sequencing identifies novel and conserved microRNAs in peanuts (Arachis hypogaea L.)," BMC Plant Biology, vol. 10, article 3, 2010.

[25] T. H. Beilharz, D. T. Humphreys, J. L. Clancy et al., "MicroRNAmediated messenger RNA deadenylation contributes to translational repression in mammalian cells," PLOS ONE, vol. 4, no. 8, article e6783, 2009.

[26] P. Sethupathy, M. Megraw, and A. G. Hatzigeorgiou, "A guide through present computational approaches for the identification of mammalian microRNA targets," Nature Methods, vol. 3, no. 11, pp. 881-886, 2006.

[27] Y. Cai, X. Yu, Q. Zhou et al., "Novel microRNAs in silkworm (Bombyx mori)," Functional and Integrative Genomics, vol. 10, no. 3, pp. 405-415, 2010.

[28] H. Chen, Y. Sun, R. Dong et al., "Mir-34a is upregulated during liver regeneration in rats and is associated with the suppression of hepatocyte proliferation," PLOS ONE, vol. 6, no. 5, article e20238, 2011.

[29] R. P. Dippold, R. Vadigepalli, G. E. Gonye, B. Patra, and J. B. Hoek, "Chronic ethanol feeding alters miRNA expression dynamics during liver regeneration," Alcoholism, Clinical and Experimental Research, vol. 37, supplement 1, pp. E59-E69, 2013.

[30] M. H. Lu, C.-Z. Li, C. J. Hu et al., "MicroRNA-27b suppresses mouse MSC migration to the liver by targeting SDF- $1 \alpha$ in vitro," Biochemical and Biophysical Research Communications, vol. 421, no. 2, pp. 389-395, 2012.

[31] F. Meng, H. Francis, S. Glaser et al., "Role of stem cell factor and granulocyte colony-stimulating factor in remodeling during liver regeneration," Hepatology, vol. 55, no. 1, pp. 209-221, 2012.

[32] B. Yuan, R. Dong, D. Shi et al., "Down-regulation of miR-23b may contribute to activation of the TGF- $\beta 1 / \mathrm{Smad} 3$ signalling pathway during the termination stage of liver regeneration," FEBS Letters, vol. 585, no. 6, pp. 927-934, 2011.

[33] I. Chaveles, A. Zaravinos, I. G. Habeos et al., "MicroRNA profiling in murine liver after partial hepatectomy," International Journal of Molecular Medicine, vol. 29, no. 5, pp. 747-755, 2012.

[34] Y. Zhu, Y. Lu, Q. Zhang et al., "MicroRNA-26a/b and their host genes cooperate to inhibit the G1/S transition by activating the pRb protein," Nucleic Acids Research, vol. 40, no. 10, pp. 4615$4625,2012$.

[35] B. Zhang, X. Pan, Q. Wang, G. P. Cobb, and T. A. Anderson, "Computational identification of microRNAs and their targets," Computational Biology and Chemistry, vol. 30, no. 6, pp. 395407, 2006.

[36] C. Wang, J. Han, C. Liu et al., "Identification of microRNAs from Amur grapes (vitis amurensis Rupr.) by deep sequencing and analysis of microRNA variations with bioinformatics," BMC Genomics, vol. 13, article 122, 2012.

[37] D. Schotte, F. A. Moqadam, E. A. M. Lange-Turenhout et al., "Discovery of new microRNAs by small RNAome deep sequencing in childhood acute lymphoblastic leukemia," Leukemia, vol. 25, no. 9, pp. 1389-1399, 2011. 
[38] B. Venkatesh, E. F. Kirkness, Y. H. Loh et al., "Ancient noncoding elements conserved in the human genome," Science, vol. 314, no. 5807, p. 1892, 2006.

[39] G. Song and L. Wang, "MiR-433 and miR-127 arise from independent overlapping primary transcripts encoded by the miR-433-127 locus," PLoS ONE, vol. 3, no. 10, article e3574, 2008.

[40] A. Stark, N. Bushati, C. H. Jan et al., "A single Hox locus in Drosophila produces functional microRNAs from opposite DNA strands," Genes and Development, vol. 22, no. 1, pp. 8-13, 2008.

[41] J. Shu, B. T. Kren, Z. Xia et al., "Genomewide microRNA downregulation as a negative feedback mechanism in the early phases of liver regeneration," Hepatology, vol. 54, no. 2, pp. 609-619, 2011.

[42] L. Wu, C. Cai, X. Wang, M. Liu, X. Li, and H. Tang, "MicroRNA142-3p, a new regulator of RAC1, suppresses the migration and invasion of hepatocellular carcinoma cells," FEBS Letters, vol. 585, no. 9, pp. 1322-1330, 2011.

[43] A. Sacconi, F. Biagioni, V. Canu et al., "miR-204 targets Bcl-2 expression and enhances responsiveness of gastric cancer," Cell Death \& Disease, vol. 3, article e423, 2012.

[44] M. Zhou, Z. Liu, Y. Zhao et al., "MicroRNA-125b confers the resistance of breast cancer cells to paclitaxel through suppression of pro-apoptotic Bcl-2 antagonist killer 1 (Bak1) expression," The Journal of Biological Chemistry, vol. 285, no. 28, pp. 21496-21507, 2010. 

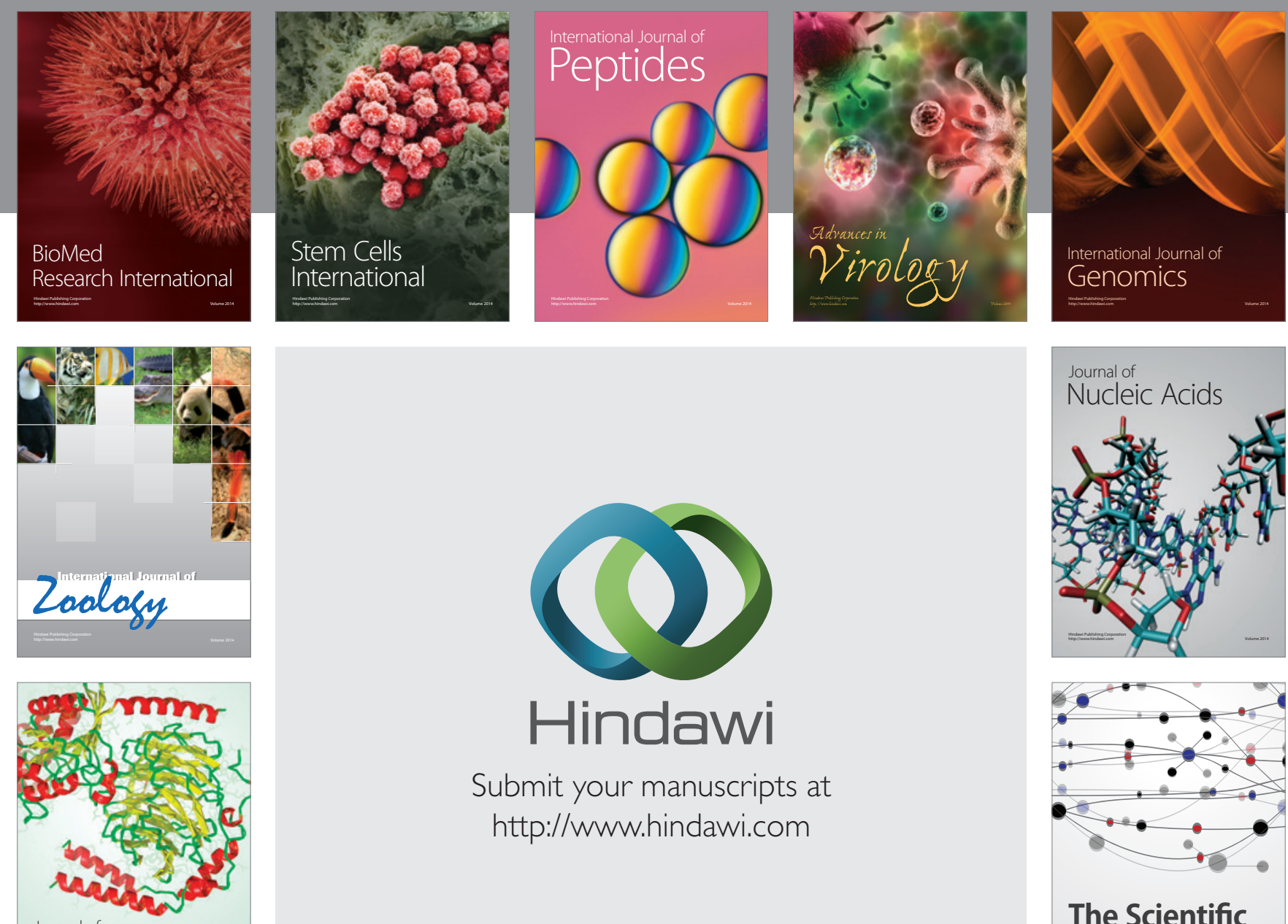

Submit your manuscripts at

http://www.hindawi.com

Journal of
Signal Transduction
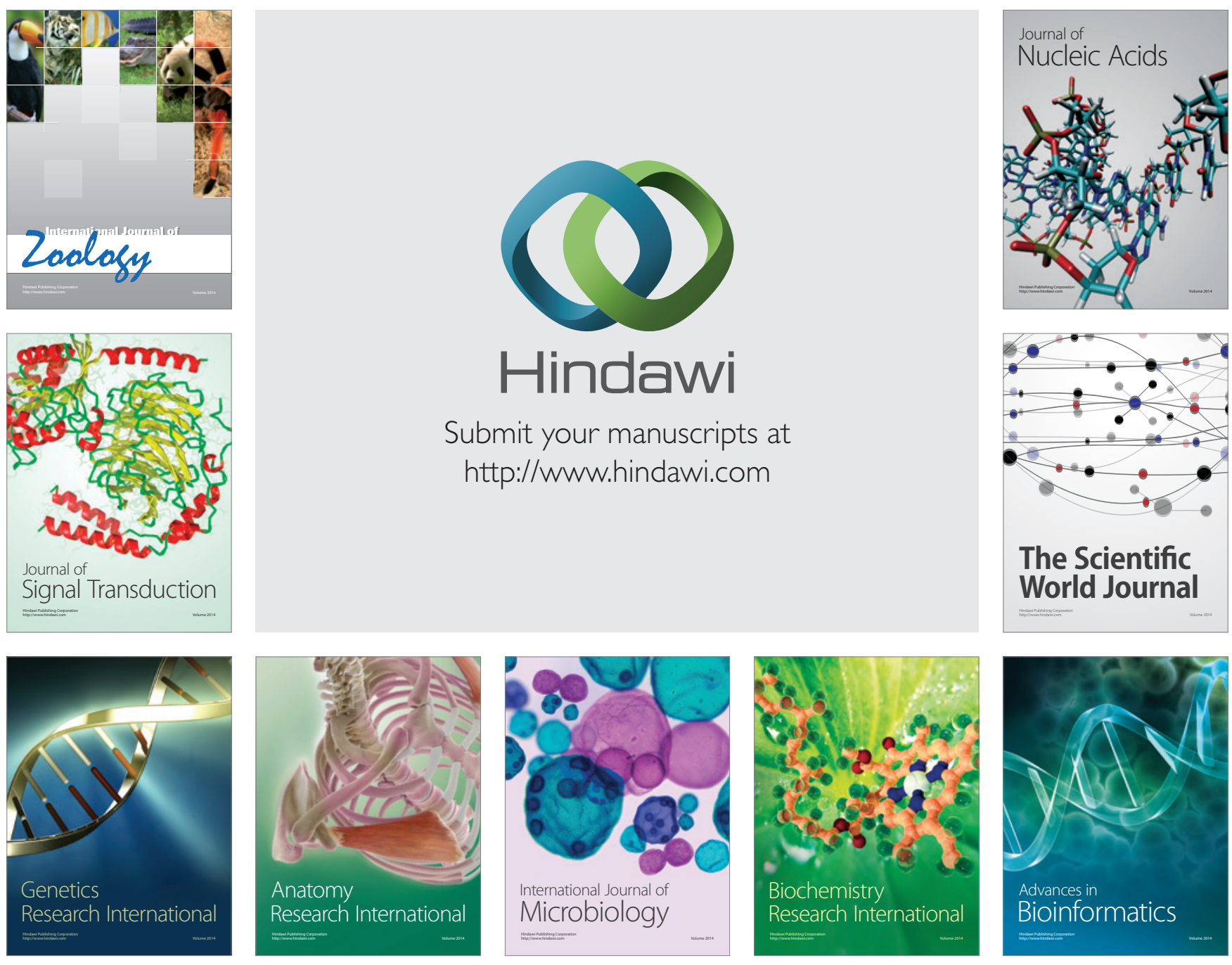

The Scientific World Journal
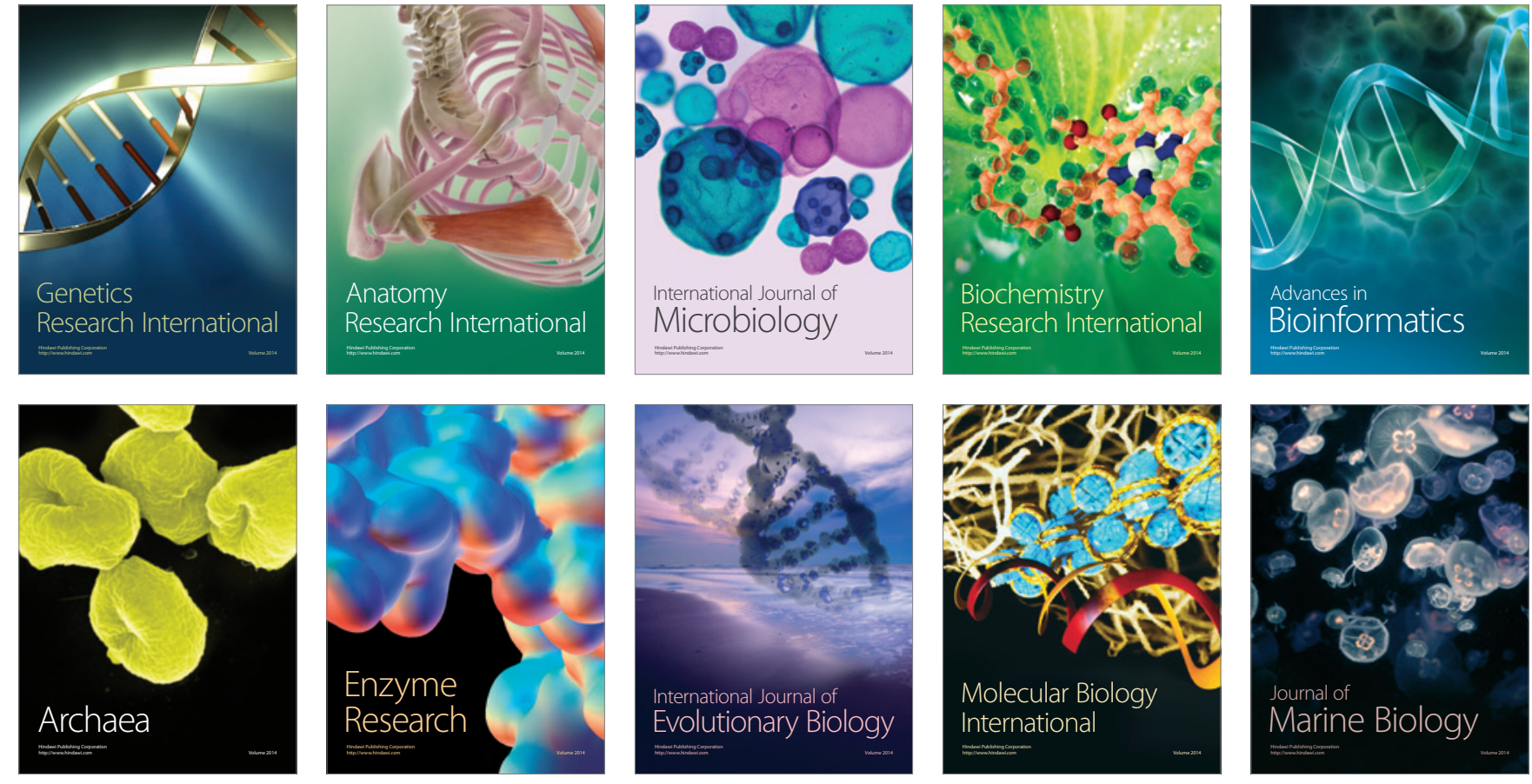